\title{
Infection, Sepsis and the Inflammatory Response: Mechanisms and Therapy
}

\begin{abstract}
Dagan O. Lonsdale ${ }^{1,2 *}$, Reya V. Shah ${ }^{1,2}$ and Jeffrey Lipman ${ }^{3,4,5}$
${ }^{1}$ Department of Clinical Pharmacology, St George's University of London, London, United Kingdom, ${ }^{2}$ Department of Critical Care, St George's University Hospitals National Health Service (NHS) Foundation Trust, London, United Kingdom,

${ }^{3}$ Department of Intensive Care, Royal Brisbane and Women's Hospital, Brisbane, QLD, Australia, ${ }^{4}$ University of Queensland Centre for Clinical Research, The University of Queensland, Brisbane, QLD, Australia, ${ }^{5}$ Division of Anaesthesiology Critical Care Emergency and Pain Medicine, Nîmes University Hospital, University of Montpellier, Nîmes, France
\end{abstract}

Sepsis secondary to bacterial infection remains a significant cause of morbidity and mortality globally. Recent decades have seen the evolution of international collaborations to improve care for these patients and identify areas for research. In this article we discuss the pathophysiology underlying the condition, review the current recommended management strategies, discuss areas of controversy, and highlight the need for ongoing research, particularly in diagnostics.

Keywords: infection, intensive \& critical care, antibiotics, sepsis, Infectious disease

\section{OPEN ACCESS}

Edited by:

Matteo Bassetti,

University of Genoa, Italy

Reviewed by:

Sunny Oteikwu Ochigbo,

University of Calabar, Nigeria

Mario Venditti,

Sapienza University of Rome, Italy

*Correspondence:

Dagan O. Lonsdale

dlonsda/@sgul.ac.uk

Specialty section:

This article was submitted to Infectious Diseases - Surveillance,

Prevention and Treatment,

a section of the journal

Frontiers in Medicine

Received: 29 July 2020 Accepted: 02 November 2020 Published: 02 December 2020

Citation:

Lonsdale DO, Shah RV and Lipman J (2020) Infection, Sepsis and the Inflammatory Response: Mechanisms and Therapy. Front. Med. 7:588863.

doi: 10.3389/fmed.2020.588863

\section{INTRODUCTION}

The global burden of bacterial infection is significant. In the UK, beta-lactams and macrolide antibiotics account for 25 million prescriptions annually, and global antibiotic prescriptions are in the billions $(1,2)$. Associated healthcare costs are considerable, accounting for over $\$ 30$ billion ( $\sim 8 \%)$ of US healthcare spending (3). At the severe end of the spectrum, sepsis is a common reason for admission to intensive care, accounting for as much as $30 \%$ of admissions to adult (4-6) and $12 \%$ of admissions to pediatric units $(7,8)$. Up to $70 \%$ of intensive care patients will receive at least one course of antibiotics during their stay, regardless of age $(9,10)$. Mortality from severe infection in adults and children remains as high as $25-30 \%(8,11)$. In neonates, infection remains one of the most common causes of death worldwide (12-14). Understanding and managing infection is therefore a core skill for physicians and healthcare professionals. In this article, we will explore the pathology, diagnosis, and management of infection and sepsis, discuss some of the complexities and challenges.

\section{INFECTION, SEPSIS, AND THE INFLAMMATORY RESPONSE}

The human response to an infection follows recognition of infectious pathogens by immune cells via pattern recognition receptors. The resulting cellular activation leads to the production of pro- (particularly IL-1 and TNF $\alpha$ ) and anti-inflammatory mediators and the subsequent recruitment and activation of other immune cells (e.g., polymorphonucleocytes and B-cells) (15). In the normal host response to infection, equilibrium is reached between pro- and anti-inflammatory processes, bactericidal activity is maximized, alongside necessary phagocytosis, and repair of damaged tissue. In sepsis, this equilibrium is lost. Localized tissue response to infection becomes systemic and the inflammatory process becomes deleterious in its own right. Sepsis being formally defined as "life-threatening 
organ dysfunction caused by a dysregulated host response to infection" (16). Effects are seen across organ and tissue types. Endothelial damage results in loss of normal homeostasis, leading to fluid leak, and tissue oedema. In the vasculature there is vasodilatation mediated through several mechanisms such as the effect of acidosis on vascular smooth muscle, induction of nitric oxide by inflammatory mediators, and adrenal insufficiency. The consequent drop in systemic vascular resistance may be compensated by increased cardiac output or compounded by myocardial depression-leading to hypotension and reduced tissue perfusion. In the lungs, fluid leak may impair gas exchange and progress to acute respiratory distress syndrome. Acute kidney injury may result from direct cytokine effects as well as damage to the microvasculature or reduced tissue perfusion and hepatic effects may further impair a dysregulated coagulation system $(15,17)$. In the brain, inflammatory mediators, hypoxia, and hypotension may all contribute to the evolution of encephalopathy. Blood dyscrasias are also common, with mechanisms not fully understood. It may be that the expansion in haematopoietic stem cells secondary to demand and the inflammatory state may actually lead to the production of dysfunctional stem cells, paradoxically leading to production of less mature cells like neutrophils (and subsequent neutropenia) (18).

The dysregulated immune response to infection is unpredictable, leading to a wide spectrum of clinical presentations, and time-course for the disease. Multiple attempts have been made to describe the clinical effects in a simplified manner that allows early recognition of the septic patient. Perhaps most notably with the concept of the systemic inflammatory response syndrome (19). The use of clinical signs (fever or hypothermia, tachycardia, tachypnoea) and readily available investigations (high or low white cell count) to identify patients with this complex physiology in as simple a manner as possible is attractive. However, the lack of specificity of the SIRS criteria to identify sepsis specifically and the prevalence of cases of sepsis that do not meet these criteria make it an imperfect diagnostic tool (20-22). This lack of specificity may well-contribute to the high prevalence of antibiotic prescriptions in hospitals and the $\operatorname{ICU}(9,10)$.

\section{DIAGNOSING SEPSIS}

In an attempt to address some of the limitations of the SIRS criteria and accompanying definitions of sepsis, a new consensus definition for sepsis was proposed in 2016-life threatening organ dysfunction caused by infection (16). Organ dysfunction was defined as an increase in sequential organ failure assessment (SOFA) score of 2 or more points. Whilst this definition may increase the sensitivity of diagnosing sepsis and identify those with the greatest mortality risk, it remains non-specific and has not been universally adopted $(23,24)$. Sepsis remains a challenge to diagnose. The search for a specific biomarker in sepsis is yet to yield success, despite hundreds of potential molecules being identified (25-27). Blood cultures are often cited as a gold standard method of identifying pathogens, but the test remains flawed in its utility in managing the early stages of sepsis given the long turn-around time and frequency of contaminated and false-positive/negative samples (28). Clinicians must therefore use signs, symptoms and supportive investigations to identify or suspect infection. This may be straightforward in the coughing, hypoxic patient with lobar consolidation identified on a chest radiograph or challenging in an elderly patient for whom dementia contributes to non-specific symptoms. Supportive signs and investigations like temperature, white cell count and inflammatory biomarkers like C-reactive protein or procalcitonin may be raised in any stress response and early antibiotics, whilst important for treatment, may impair the identification of a pathogen from samples cultured after administration.

\section{THERAPIES}

The decision on where to treat a person who has sepsis will largely depend on local hospital resources and the mode and route of presentation. Many cases will present to the emergency department directly but management of cases identified in the community or in hospital inpatients merit consideration. Regardless of the route to identification of a case, consensus remains that early treatment of the infection and provision of supportive care improves outcome $(24,29,30)$.

\section{Antimicrobials}

The most recent surviving sepsis guidelines recommend administration of intravenous antimicrobials within $1 \mathrm{~h}$ of identification of sepsis (29). This recommendation is supported by multiple observational studies that show an association between delay in antimicrobial administration and increase in mortality (30-32). Choice of antimicrobial should be directed to provide coverage for the most likely pathogen that has caused the septic state. Mirroring the heterogeneity of the clinical presentation of sepsis, the range of possible pathogens is myriad and will be dependent on the patient, their presentation and previous medical history alongside local factors such as antimicrobial resistance patterns. Given this heterogeneity and the fact that pathogens are not usually identified at the time of diagnosis of sepsis, it is not possible to recommend a specific antibiotic or antibiotic combinations. Broad-spectrum coverage is usually therefore necessary, with choice of $\operatorname{drug}(\mathrm{s})$ directed at potential site of infection and coverage of risk factors. This may require the use of multiple agents, for example the combination of broad spectrum $B$ lactam with vancomycin where MRSA is suspected and addition of antifungals where invasive fungal disease may be present (for example where immunocompromised state exists). Choice of agent should be taken in line with local prescribing guidelines. Dose and mode of antibiotic administration continues to evolve in the management of sepsis. The one-size fits all dosing strategy used in the management of community infection cannot hold in the management of sepsis where profound alterations to antimicrobial pharmacokinetics are likely secondary to both organ dysfunction and changes in volume of distribution from altered volume status (secondary to the disease and fluid resuscitation in its management) 
TABLE 1 | Commonly used antibiotics and the pharmacokinetic-pharmacodynamic index associated with therapeutic success.

\begin{tabular}{lc}
\hline Antibiotic class & Pharmacokinetic-pharmacodynamic index \\
\hline Aminoglycosides & $\mathrm{C}_{\text {MAX }}: \mathrm{MIC}$ \\
$\beta$-lactams & $\mathrm{T}>\mathrm{MIC}$ \\
Fluroquinolones & $\mathrm{C}_{\mathrm{MAX}}: \mathrm{MIC}$ \\
Glycopeptides & AUC/MIC \\
Macrolides & AUC/MIC
\end{tabular}

Table adapted from Roberts and Lipman (37) and Asin-Prieto et al. (38). C MAx, maximum concentration; MIC, minimum inhibitory concentration of suspected pathogen; T, time; AUC, area under the time-concentration curve.

$(29,33)$. Whilst organ dysfunction associated with sepsis can lead to accumulation of antimicrobials, this is not universal. Altered antimicrobial pharmacokinetics in sepsis has been shown to reduce plasma concentration to below levels considered therapeutic $(34,35)$ and failure to achieve therapeutic plasma concentrations has been associated with failure of therapy (36). It is therefore recommended that dose and frequency of administration are considered and individualized from the outset of treatment. These considerations should include the pharmacokinetic-pharmacodynamic relationship between antimicrobial and pathogen (Table 1) such that dose and dosing regimen are optimized. For example, the pharmacokineticpharmacodynamic index associated with successful bacterial kill of $ß$-lactams is time with drug concentration above the minimum inhibitory concentration of the target bacteria. Frequent (and adequate) dosing is therefore required to maintain an appropriate concentration time profile for B-lactams. A phase III clinical trial is ongoing into the utility of continuous infusions (39). Completely individualized treatment courses are difficult to achieve without rapid therapeutic drug monitoring, which is often not routinely available, save perhaps for the monitoring for harm of aminoglycosides. Duration of therapy should minimize exposure to broad-spectrum antibiotics where possible. This should include switching to narrow spectrum agents where pathogens and susceptibility are identified and minimizing the duration of multi-agent regimens by, for example, reducing to single agent cover as shock resolves and there is clinical improvement. Stewardship of antimicrobials in this way will minimize the potential for emergence of resistant pathogens. Indeed, such stewardship should be considered as important a place in therapy as initial choice and dose of antibiotics, since infection with multi-drug resistant pathogens is associated with increased hospital length of stay and mortality $(40,41)$ and alteration in commensal microbiome to resistant pathogens is rapid-as quickly as within 1 day of exposure to imipenem in one study (42).

\section{Source Control}

Where sepsis is caused by a focus of infection that is amenable to source control through surgical or other intervention (e.g., removal of infected indwelling catheters), source control should occur as quickly as practical (within 6-12 h) (43-46).

\section{Fluid Therapy}

Whilst there are few clinicians who would advocate removing fluids from the armory of sepsis management, the choice, amount and rate of administration of fluid remains controversial and it is an area of need for ongoing research. The principle of restoring a circulating volume to provide adequate tissue perfusion in the vasodilated and fluid shifting septic state is sound, but for some patients with sepsis cardiac output may be elevated and tissue blood flow may be increased and oxygen delivery satisfactory. The one size fits all fluid dose of $30 \mathrm{ml} / \mathrm{kg}$ recommended in the most recent surviving sepsis guidelines is, therefore, controversial. Indeed, by the guide's own acknowledgment the evidence to support this recommendation is "low quality" (29) and there is evidence of harm of over resuscitation in some settings $(5,47)$. A gold standard guide to adequacy of resuscitative volume does not exist. Raised serum lactate, whilst associated with worse outcomes in sepsis, may be elevated in the setting of catecholamines (endogenous or exogenous), hepatic failure, or altered cellular metabolism in sepsis $(29,48)$. It is therefore an imperfect guide to volume state. Indeed, a recent trial found no difference in mortality outcome between septic patients in whom fluid resuscitation targeted lactate normalization vs. normal capillary refill time (49). It would seem prudent, as with recommendations on antimicrobial and vasopressor administration, that fluid dosing in sepsis should be personalized. This entails the use of small bolus fluid administration (250-500 mL) with frequent reassessment. The perfect assessment modality does not exist, simple measures like capillary refill time or straight leg raise tests may well be as useful as more complex or invasive assessment modalities such as point of care ultrasound or haemodynamic monitoring software.

Crystalloids infusions are favored over albumin and synthetic colloids as the initial fluid of choice, although there is insufficient evidence to guide choice of crystalloid in sepsis. Balanced solutions are often preferred to high chloride $(0.9 \%$ sodium chloride) infusions but direct head to head trials in sepsis are missing. Albumin may be considered as a fluid choice, but high-quality evidence of benefit over crystalloids is lacking $(29,50,51)$.

\section{Target Blood Pressure}

A target mean arterial pressure has of $65 \mathrm{mmHg}$ has been advocated in sepsis (29). This target is based on the principal of reduced tissue perfusion with lower pressures. Trials of higher target mean arterial pressure have not shown clinically meaningful benefit and some evidence of harm from adverse drug effects (52-54). However, it may be that a lower target is acceptable. In the recently published "65-trial," a lower target mean arterial pressure of $60 \mathrm{mmHg}$ was tested against the 65 $\mathrm{mmHg}$ clinical standard in older (over-65) critically ill patients with vasodilatory shock (55). There was no mortality difference shown between the two targets. The results of this study has been cited as supporting personalisation of pressure targets, accepting lower bound of $60 \mathrm{mmHg}$ in some instances (56), although this has not been adopted in the recent COVID-19 interim guidance issued by the surviving sepsis group (57). 


\section{Vasopressors}

Norepinephrine is generally accepted as the first-line vasoactive agent in fluid-refractory septic shock in adults (29), with the therapeutic aim of restoring mean arterial pressure and tissue perfusion. Superiority of norepinephrine over dopamine has been demonstrated in systematic reviews, both in terms of survival outcome and reduced adverse effects $(58,59)$. The surviving sepsis continue to include a recommendation for the use of dopamine as an alternative in select patients with low risk of tachyarrhythmias, although the guidelines do not make recommendations on how to select these patients (29). Vasopressin may be considered as a second line agent in vasodilatory shock that persists despite norepinephrine. There is no mortality benefit of one drug above the other and vasopressin is probably best considered norepinephrine sparing $(29,60,61)$. Data guiding the norepinephrine dose at which a second agent should be instituted is lacking. The surviving sepsis authors advocate an upper dose limit of 0.03 units/min of vasopressin, this was the dose used in the intervention arm of the VASST trial (61). The more recent VANISH trial used an upper limit of 0.06 units/min but showed numerically higher incidence of digital and mesenteric ischaemia compared with norepinephrine doses (60). Epinephrine is an alternative second line agent. For the subset of patients with myocardial impairment and low cardiac output secondary to sepsis, the surviving sepsis guidelines suggest considering dobutamine as an inotrope.

\section{Other Potential Therapies}

A plethora of additional agents have been advocated as tools in the armory for the treatment of sepsis and shock associated with sepsis. Corticosteroids, immunoglobulins, vitamin C (with or without thiamine) are some more common recent examples. None have been shown to provide meaningful mortality benefit in high quality randomized controlled trials. Corticosteroids retain a place for those with adrenal insufficiency (chronic steroid use, Addison's disease etc.). Some also advocate corticosteroid use (200 mg/day for 7-days) in septic shock refractory to fluid

\section{REFERENCES}

1. Van Boeckel TP, Gandra S, Ashok A, Caudron Q, Grenfell BT, Levin SA, et al. Global antibiotic consumption 2000 to 2010: an analysis of national pharmaceutical sales data. Lancet Infect Dis. (2014) 14:74250. doi: 10.1016/S1473-3099(14)70780-7

2. National Statistics. Prescription Cost Analysis, England 2016. (2017). Available online at: https://digital.nhs.uk/data-and-information/publications/ statistical/prescription-cost-analysis/prescription-cost-analysis-england2016

3. Torio C, Andrews R. National Inpatient Hospital Costs: The Most Expensive Conditions by Payer, 2011: Statistical Brief \#160. (2013). Available online at: https://www.ncbi.nlm.nih.gov/books/NBK169005/ (accessed Feburary 1, 2018).

4. Padkin A, Goldfrad C, Brady AR, Young D, Black N, Rowan K. Epidemiology of severe sepsis occurring in the first $24 \mathrm{hrs}$ in intensive care units in England, Wales, and Northern Ireland. Crit Care Med. (2003) 31:23328. doi: 10.1097/01.CCM.0000085141.75513.2B

5. Vincent JL, Sakr Y, Sprung CL, Ranieri VM, Reinhart K, Gerlach H, et al. Sepsis in European intensive care units: results of the SOAP study. Crit Care Med. (2006) 34:344-53. doi: 10.1097/01.CCM.0000194725.48928.3A and vasopressor therapy, citing shorter time to resolution of shock and shorter ICU stay $(62,63)$. There does not appear to be a risk of increased secondary infection with this approach, although hyperglycaemia and hypernatraemia are more common with steroid use (63). Multiple trials investigating the effect of vitamin $\mathrm{C}$ in sepsis are ongoing.

\section{Supportive ICU Care}

Septic patients should receive standard ICU care bundles that include venous thromboembolism and stress ulcer prophylaxis, glucose control and sedation care for ventilated patients.

\section{CONCLUSION AND FUTURE WORK}

Sepsis remains a challenging condition to manage. Heterogeneity of presentation, similarity to other inflammatory states and disease time-course makes diagnosis challenging and mortality remains high despite global efforts in improving treatment. International collaboration has been extraordinary and provides a good starting point for management. Treatment recommendations are not without controversy and are probably best used as a platform to design personalized treatment regimens, rather than rigidly sticking to protocols. Ongoing work must focus on improved diagnostics, alongside novel therapeutics. The need for an sensitive and specific biomarker seems most pressing, as it would enable appropriate management for the individual patient, assist in antimicrobial stewardship to protect drugs for the population and provide the ability to more accurately recruit participants with true sepsis to interventional trials.

\section{AUTHOR CONTRIBUTIONS}

All authors listed have made a substantial, direct and intellectual contribution to the work, and approved it for publication.
6. Intensive Care National Audit \& Research Centre (ICNARC): Case Mix Programme. (2009). Available online at: https://www.icnarc.org/Our-Audit/ Audits/Cmp/Our-National-Analyses/Sepsis (accessed December 05, 2016).

7. Schlapbach LJ, Straney L, Alexander J, MacLaren G, Festa M, Schibler A, et al. Mortality related to invasive infections, sepsis, and septic shock in critically ill children in Australia and New Zealand 2002-13: a multicentre retrospective cohort study. Lancet Inect Dis. (2015) 15:4654. doi: 10.1016/S1473-3099(14)71003-5

8. Weiss SL, Fitzgerald JC, Pappachan J, Wheeler D, Jaramillo-Bustamante JC, Salloo A, et al. Global epidemiology of pediatric severe sepsis: the sepsis prevalence, outcomes, and therapies study. Am J Respir Crit Care Med. (2015) 191:1147-57. doi: 10.1164/rccm.201412-2323OC

9. Vincent JL, Rello J, Marshall J, Silva E, Anzueto A, Martin CD, et al. International study of the prevalence and outcomes of infection in intensive care units. J Am Med Assoc. (2009) 302:2323-9. doi: 10.1001/jama.2009. 1754

10. Cantey JB, Wozniak PS, Sánchez PJ. Prospective surveillance of antibiotic use in the neonatal intensive care unit: results from the SCOUT study. Paediatr Infect Dis J. (2015) 34:267-72. doi: 10.1097/INF.0000000000000542

11. Stevenson EK, Rubenstein AR, Radin GT, Wiener RS, Walkey AJ. Two decades of mortality trends among patients with severe 
sepsis: a comparative meta-analysis*. Crit Care Med. (2014) 42:625-31. doi: 10.1097/CCM.0000000000000026

12. Depani SJ, Ladhani S, Heath PT, Lamagni TL, Johnson AP, Pebody RG, et al. The contribution of infections to neonatal deaths in England and Wales. Pediatr Infect Dis J. (2011) 30:345-7. doi: 10.1097/INF.0b013e3182102249

13. Patel RM, Kandefer S, Walsh MC, Bell EF, Carlo WA, Laptook AR, et al. Causes and timing of death in extremely premature infants from 2000 through 2011. N Engl J Med. (2015) 372:331-40. doi: 10.1056/NEJMoa1403489

14. Oza S, Lawn JE, Hogan DR, Mathers C, Cousens SN. Neonatal cause-of-death estimates for the early and late neonatal periods for 194 countries: 2000-2013. Bull World Health Organ. (2015) 93:19-28. doi: 10.2471/BLT.14.139790

15. Cinel I, Dellinger RP. Advances in pathogenesis and management of sepsis. Curr Opin Infect Dis. (2007) 20:345-52. doi: 10.1097/QCO.0b013e32818be70a

16. Singer M, Deutschman CS, Seymour CW, Shankar-Hari M, Annane $\mathrm{D}$, Bauer $\mathrm{M}$, et al. The third international consensus definitions for sepsis and septic shock (sepsis-3). J Am Med Assoc. (2016) 315:80110. doi: 10.1001/jama.2016.0287

17. Gyawali B, Ramakrishna K, Dhamoon AS. Sepsis: the evolution in definition, pathophysiology, and management. SAGE Open Med. (2019) 7:2050312119835043. doi: 10.1177/2050312119835043

18. Rodriguez S, Chora A, Goumnerov B, Mumaw C, Goebel WS, Fernandez $\mathrm{L}$, et al. Dysfunctional expansion of hematopoietic stem cells and block of myeloid differentiation in lethal sepsis. Blood. (2009) 114:406476. doi: 10.1182/blood-2009-04-214916

19. Bone RC, Balk RA, Cerra FB, Dellinger RP, Fein AM, Knaus WA, et al. Definitions for sepsis and organ failure and guidelines for the use of innovative therapies in sepsis. The accp/sccm consensus conference committee. American college of chest physicians/society of critical care medicine. Chest. (1992) 101:1644-55. doi: 10.1378/chest.101.6.1644

20. Churpek MM, Zadravecz FJ, Winslow C, Howell MD, Edelson DP. Incidence and prognostic value of the systemic inflammatory response syndrome and organ dysfunctions in ward patients. Am J Respir Crit Care Med. (2015) 192:958-64. doi: 10.1164/rccm.201502-0275OC

21. Kaukonen KM, Bailey M, Pilcher D, Cooper DJ, Bellomo R. Systemic inflammatory response syndrome criteria in defining severe sepsis. $N$ Engl J Med. (2015) 372:1629-38. doi: 10.1056/NEJMoa1415236

22. Fernando SM, Tran A, Taljaard M, Cheng W, Rochwerg B, Seely AJE, et al. Prognostic accuracy of the quick sequential organ failure assessment for mortality in patients with suspected infection. Ann Intern Med. (2018) 168:266-75. doi: 10.7326/M17-2820

23. Marik PE, Taeb AM. SIRS, qSOFA and new sepsis definition. J Thorac Dis. (2017) 9:943-5. doi: 10.21037/jtd.2017.03.125

24. Vincent JL. The clinical challenge of sepsis identification and monitoring. PLoS Med. (2016) 13:e1002022. doi: 10.1371/journal.pmed.1002022

25. Morriello F, Marshall J. Biomarkers in sepsis: a systematic review. Crit Care. (2015) 19:P50. doi: 10.1186/cc14130

26. Pierrakos C, Vincent JL. Sepsis biomarkers: a review. Crit Care. (2010) 14:R15. doi: 10.1186/cc8872

27. McHugh L, Seldon TA, Brandon RA, Kirk JT, Rapisarda A, Sutherland AJ, et al. A Molecular host response assay to discriminate between sepsis and infection-negative systemic inflammation in critically Ill patients: discovery and validation in independent cohorts. PLoS Med. (2015) 12:e1001916. doi: 10.1371/journal.pmed.1001916

28. Gunsolus IL, Sweeney TE, Liesenfeld O, Ledeboer NA. Diagnosing and managing sepsis by probing the host response to infection: advances, opportunities, and challenges. J Clin Microbiol. (2019) 57:e00425-19. doi: 10.1128/JCM.00425-19

29. Rhodes A, Evans LE, Alhazzani W, Levy MM, Antonelli M, Ferrer R, et al. Surviving sepsis campaign: international guidelines for management of sepsis and septic shock: 2016. Crit Care Med. (2017) 45:486552. doi: 10.1097/CCM.0000000000002255

30. Ferrer R, Martin-Loeches I, Phillips G, Osborn TM, Townsend S, Dellinger $\mathrm{RP}$, et al. Empiric antibiotic treatment reduces mortality in severe sepsis and septic shock from the first hour: results from a guideline-based performance improvement program. Crit Care Med. (2014) 42:174955. doi: $10.1097 / C C M .0000000000000330$

31. Kumar A, Roberts D, Wood KE, Light B, Parrillo JE, Sharma S, et al. Duration of hypotension before initiation of effective antimicrobial therapy is the critical determinant of survival in human septic shock. Crit Care Med. (2006) 34:1589-96. doi: 10.1097/01.CCM.0000217961.75225.E9

32. Garnacho-Montero J, Gutiérrez-Pizarraya A, Escoresca-Ortega A, FernándezDelgado E, López-Sánchez JM. Adequate antibiotic therapy prior to ICU admission in patients with severe sepsis and septic shock reduces hospital mortality. Crit Care. (2015) 19:302. doi: 10.1186/s13054-015-1000-z

33. Crass RL, Rodvold KA, Mueller BA, Pai MP. Renal dosing of antibiotics: are we jumping the gun? Clin Infect Dis. (2019) 68:1596-602. doi: 10.1093/cid/ciy790

34. Taccone FS, Laterre PF, Dugernier T, Spapen H, Delattre I, Wittebole X, et al. Insufficient $\beta$-lactam concentrations in the early phase of severe sepsis and septic shock. Crit Care. (2010) 14:R126. doi: 10.1186/cc9091

35. Sime FB, Roberts MS, Peake SL, Lipman J, Roberts JA. Does betalactam pharmacokinetic variability in critically Ill patients justify therapeutic drug monitoring? A systematic review. Ann Intensive Care. (2012) 2:35. doi: $10.1186 / 2110-5820-2-35$

36. Roberts JA, Paul SK, Akova M, Bassetti M, De Waele JJ, Dimopoulos G, et al. DALI: defining antibiotic levels in intensive care unit patients: are current beta-lactam antibiotic doses sufficient for critically ill patients? Clin Infect Dis. (2014) 58:1072-83. doi: 10.1093/cid/ciu027

37. Roberts JA, Lipman J. Pharmacokinetic issues for antibiotics in the critically ill patient. Crit Care Med. (2009) 37:84051. doi: 10.1097/CCM.0b013e3181961bff

38. Asin-Prieto E, Rodriguez-Gascon A, Troconiz IF, Soraluce A, Maynar J, Sanchez-Izquierdo JA, et al. Population pharmacokinetics of piperacillin and tazobactam in critically ill patients undergoing continuous renal replacement therapy: application to pharmacokinetic/pharmacodynamic analysis. J Antimicrob Chemother. (2014) 69:180-9. doi: 10.1093/jac/dkt304

39. Lipman J, Brett SJ, De Waele JJ, Cotta MO, Davis JS, Finfer S, et al. A protocol for a phase 3 multicentre randomised controlled trial of continuous versus intermittent $\beta$-lactam antibiotic infusion in critically ill patients with sepsis: BLING III. Crit Care Resusc. (2019) 21:63-8.

40. Barrasa-Villar JI, Aibar-Remón C, Prieto-Andrés P, Mareca-Doñate R, Moliner-Lahoz J. Impact on morbidity, mortality, and length of stay of hospital-acquired infections by resistant microorganisms. Clin Infect Dis. (2017) 65:644-52. doi: 10.1093/cid/cix411

41. Neidell MJ, Cohen B, Furuya Y, Hill J, Jeon CY, Glied S, et al. Costs of healthcare- and community-associated infections with antimicrobial-resistant versus antimicrobial-susceptible organisms. Clin Infect Dis. (2012) 55:80715. doi: $10.1093 / \mathrm{cid} / \mathrm{cis} 552$

42. Armand-Lefèvre L, Angebault C, Barbier F, Hamelet E, Defrance G, Ruppé $\mathrm{E}$, et al. Emergence of imipenem-resistant gram-negative bacilli in intestinal flora of intensive care patients. Antimicrob Agents Chemother. (2013) 57:148895. doi: 10.1128/AAC.01823-12

43. Azuhata T, Kinoshita K, Kawano D, Komatsu T, Sakurai A, Chiba Y, et al. Time from admission to initiation of surgery for source control is a critical determinant of survival in patients with gastrointestinal perforation with associated septic shock. Crit Care. (2014) 18:R87. doi: 10.1186/cc13854

44. Lagunes L, Encina B, Ramirez-Estrada S. Current understanding in source control management in septic shock patients: a review. Ann Transl Med. (2016) 4:330. doi: 10.21037/atm.2016.09.02

45. Martínez ML, Ferrer R, Torrents E, Guillamat-Prats R, Gomà G, Suárez D, et al. Impact of source control in patients with severe sepsis and septic shock. Crit Care Med. (2017) 45:11-9. doi: 10.1097/CCM.0000000000002011

46. Bloos F, Thomas-Rueddel D, Rueddel H, Engel C, Schwarzkopf D, Marshall J, et al. Impact of compliance with infection management guidelines on outcome in patients with severe sepsis: a prospective observational multi-center study. Crit Care. (2014) 18:R42. doi: 10.1186/cc13755

47. Maitland K, Kiguli S, Opoka RO, Engoru C, Olupot-Olupot P, Akech SO, et al. Mortality after fluid bolus in African children with severe infection. $N$ Engl J Med. (2011) 364:2483-95. doi: 10.1056/NEJMoa1101549

48. Spiegel R, Gordon D, Marik PE. The origins of the Lacto-Bolo reflex: the mythology of lactate in sepsis. J Thorac Dis. (2020) 12(Suppl. 1):S4853. doi: $10.21037 /$ jtd.2019.11.48

49. Hernández G, Ospina-Tascón GA, Damiani LP, Estenssoro E, Dubin A, Hurtado J, et al. Effect of a resuscitation strategy targeting peripheral perfusion status vs serum lactate levels on 28-day mortality among patients with septic shock: the ANDROMEDA-SHOCK randomized clinical trial. JAMA. (2019) 321:654-64. doi: 10.1001/jama.2019.0071 
50. A comparison of albumin and saline for fluid resuscitation in the intensive care unit. $N$ Engl J Med. (2004) 350:2247-56. doi: 10.1056/NEJMoa 040232

51. Caironi P, Tognoni G, Masson S, Fumagalli R, Pesenti A, Romero M, et al. Albumin replacement in patients with severe sepsis or septic shock. $N$ Engl J Med. (2014) 370:1412-21. doi: 10.1056/NEJMoa1305727

52. LeDoux D, Astiz ME, Carpati CM, Rackow EC. Effects of perfusion pressure on tissue perfusion in septic shock. Crit Care Med. (2000) 28:272932. doi: 10.1097/00003246-200008000-00007

53. Bourgoin A, Leone M, Delmas A, Garnier F, Albanèse J, Martin C. Increasing mean arterial pressure in patients with septic shock: effects on oxygen variables and renal function. Crit Care Med. (2005) 33:7806. doi: 10.1097/01.CCM.0000157788.20591.23

54. Asfar P, Meziani F, Hamel JF, Grelon F, Megarbane B, Anguel N, et al. High versus low blood-pressure target in patients with septic shock. $N$ Engl J Med. (2014) 370:1583-93. doi: 10.1056/NEJMoa1312173

55. Lamontagne F, Richards-Belle A, Thomas K, Harrison DA, Sadique MZ, Grieve RD, et al. Effect of reduced exposure to vasopressors on 90-day mortality in older critically Ill patients with vasodilatory hypotension: a randomized clinical trial. JAMA. (2020) 323:938-49. doi: 10.1001/jama.2020.0930

56. Marshall JC. Choosing the best blood pressure target for vasopressor therapy. JAMA. (2020) 323:931-3. doi: 10.1001/jama.2019.22526

57. Alhazzani W, Moller MH, Arabi YM, Loeb M, Gong MN, Fan E, et al. Surviving sepsis campaign: guidelines on the management of critically ill adults with coronavirus disease 2019 (COVID-19). Crit Care Med. (2020) 48:E440-69. doi: 10.1097/CCM.0000000000004363

58. Avni T, Lador A, Lev S, Leibovici L, Paul M, Grossman A. Vasopressors for the treatment of septic shock: systematic review and meta-analysis. PLOS ONE. (2015) 10:e0129305. doi: 10.1371/journal.pone.0129305

59. Vasu TS, Cavallazzi R, Hirani A, Kaplan G, Leiby B, Marik PE. Norepinephrine or dopamine for septic shock: systematic review of randomized clinical trials. J Intensive Care Med. (2011) 27:172-8. doi: 10.1177/0885066610 396312

60. Gordon AC, Mason AJ, Thirunavukkarasu N, Perkins GD, Cecconi M, Cepkova $\mathrm{M}$, et al. Effect of early vasopressin vs norepinephrine on kidney failure in patients with septic shock: the VANISH randomized clinical trial. JAMA. (2016) 316:509-18. doi: 10.1001/jama.2016.10485

61. Russell JA, Walley KR, Singer J, Gordon AC, Hébert PC, Cooper DJ, et al. Vasopressin versus norepinephrine infusion in patients with septic shock. $N$ Engl J Med. (2008) 358:877-87. doi: 10.1056/NEJMoa067373

62. Venkatesh B, Finfer S, Cohen J, Rajbhandari D, Arabi Y, Bellomo R, et al. Adjunctive glucocorticoid therapy in patients with septic shock. N Engl J Med. (2018) 378:797-808. doi: 10.1056/NEJMoa1705835

63. Rygård SL, Butler E, Granholm A, Møller MH, Cohen J, Finfer S, et al. Low-dose corticosteroids for adult patients with septic shock: a systematic review with meta-analysis and trial sequential analysis. Intensive Care Med. (2018) 44:1003-16. doi: 10.1007/s00134-018-5 $197-6$

Conflict of Interest: JL received honoraria for lectures from MSD and Pfizer, and Institutional support from MSD.

The remaining authors declare that the research was conducted in the absence of any commercial or financial relationships that could be construed as a potential conflict of interest.

Copyright (c) 2020 Lonsdale, Shah and Lipman. This is an open-access article distributed under the terms of the Creative Commons Attribution License (CC BY). The use, distribution or reproduction in other forums is permitted, provided the original author(s) and the copyright owner(s) are credited and that the original publication in this journal is cited, in accordance with accepted academic practice. No use, distribution or reproduction is permitted which does not comply with these terms. 